\title{
Metformin and colorectal cancer
}

\author{
Gastón AMABLE*; Eduardo MARTÍNEZ-LEÓN; María E. PICCO; Osvaldo REY* \\ Consejo Nacional de Investigaciones Científicas y Técnicas, Universidad de Buenos Aires, Instituto de Inmunología, Genética y Metabolismo, Facultad de \\ Farmacia y Bioquímica, Hospital de Clínicas “José de San Martín”, Ciudad Autónoma de Buenos Aires, CP1120, Argentina
}

Key words: Metformin, $\beta$-Catenin, E-Cadherin, Colorectal cancer, AMPK, PI3K/AKT, FAK

\begin{abstract}
Colorectal cancer (CRC) is one of the main causes of cancer-related mortality in the developed world despite recent developments in detection and treatment. Several epidemiological studies indicate that metformin, a widely prescribed antidiabetic drug, exerts a protective effect on different cancers including CRC. Furthermore, a recent double-blind placebo-controlled, randomized trial showed that metformin significantly decreased colorectal adenoma recurrence. Studies exploring the mechanism of action of metformin in cells derived from different types of cancers reported many effects including respiratory chain complex 1 inhibition, Akt phosphorylation inhibition, ATP depletion, PKA activation and Wnt signaling inhibition. However, many of these results were obtained employing metformin at concentrations several fold higher than those achieved in target tissues in diabetic patients receiving therapeutic recommended doses of metformin. In contrast, recent studies obtained with metformin at concentrations compatible with those detected in human intestines revealed that metformin elicit responses that target $\beta$-catenin, PI3K/Akt, E-cadherin, p120-catenin and focal adhesion kinase which are key molecules and signaling pathways associated to colorectal cancer development. This brief review revisit several know aspects as well as novel ones on the effects of metformin on cancer cells.
\end{abstract}

\section{Introduction}

Cancer is a leading and growing cause of morbidity and mortality worldwide (Bray et al., 2018). Risk factors associated to cancer development include non-modifiable factors such as age and genetic background along with modifiable factors that include limited physical activity, poor dietary habits, obesity, metabolic syndrome and type II diabetes mellitus (T2DM) (Aleman et al., 2014; Gonzalez et al., 2017). T2DM, a chronic disease that will affect by 2040 up to $\approx 642$ million people worldwide (Unnikrishnan et al., 2017), is distinguished by hyperglycemia, hyperinsulinemia, insulin resistance and by an increase in the bioavailability of insulin-like growth factor-1 (IGF-1) and overexpression of the insulin receptor (IR). The binding of insulin and IGF to their receptors, or hybrid IR/IGF receptors, activate the phosphoinositide 3-kinase (PI3K)/ protein kinase $\mathrm{B}(\mathrm{Akt}) /$ mammalian target of rapamycin (mTOR) and mitogen-activated protein kinase (MAPK) signaling pathways promoting diverse cellular responses

\footnotetext{
*Address correspondence to: Osvaldo Rey, osrey@ucla.edu

${ }^{\#}$ These authors contributed equally to this work

Received: 05 May 2021; Accepted: 10 August 2021
}

including proliferation (Cohen and LeRoith, 2012; Gallagher and LeRoith, 2011).

Metformin (1,1-dimethylbiguanide hydrochloride) is the drug most commonly prescribed to treat hyperglycemia in T2DM patients. After oral administration of therapeutic doses (1,000-2,250 $\mathrm{mg}$ /day), metformin is absorbed by intestinal enterocytes reaching the liver through the portal vein. In the kidney, metformin is absorbed from the circulation and excreted into the urine. The concentration of metformin in portal vein can reach $40-70 \mu \mathrm{M}$ whereas in systemic plasma fluctuates between 10-40 $\mu \mathrm{M}$ ( $\mathrm{He}$ and Wondisford, 2015). In contrast, metformin can reach in intestinal tissue concentrations up to 150 fold higher than in plasma (Paleari et al., 2018).

Metformin reduces blood glucose levels by inhibiting hepatic gluconeogenesis via activation of the serine-threonine liver kinase B1 (LKB1)/AMP-activated protein kinase (AMPK), a conserved regulator of the cellular response to low energy that is activated when ATP concentrations decrease and 5'AMP concentrations increase in response to nutrient deprivation, hypoxia and metformin administration (Cusi et al., 1996; He et al., 2009; Hundal et al., 2000; Shaw et al., 2005; Zhou et al., 2001). There are other proposed mechanisms by which metformin suppresses gluconeogenesis independent of AMPK like, for example, by decreasing ATP and increasing 
AMP levels which leads to adenylate cyclase inhibition (Foretz et al., 2010; Johanns et al., 2016; Miller et al., 2013). Other studies indicated that metformin inhibits the respiratory chain complex 1, proinflammatory responses, cellular proliferation and that interferes with mechanisms associated to autoimmune diseases, such as the $\mathrm{T}$ helper 17/regulatory $\mathrm{T}$ cell balance, germinal centers formation, autoantibodies production, macrophage polarization and cytokine synthesis (El-Mir et al., 2000; Isoda et al., 2006; Park et al., 2019; Marcucci et al., 2020; Ursini et al., 2018). Other effects of metformin include suppression of cancer stem cells in some cancers, Akt phosphorylation and $\beta$-cateninmediated signaling (King et al., 2006; Melnik et al., 2018; Takatani et al., 2011; Saini and Yang, 2018). Regarding the effects of metformin upon $\beta$-catenin, several reports indicate that metformin down-regulates its expression in different cell types including endometrial cancer cells, osteoblast-like Saos-2 cells and colon carcinoma RKO cells as well as the transcriptional activity of c-MYC and $\beta$-catenin/TCF-Lef reporters in epithelial ovarian cancer cells (Conza et al., 2021; Park et al., 2019; Takatani et al., 2011; Garrido et al., 2020). Several studies also indicate that metformin halt the conversion of oral premalignant lesions into head and neck squamous cell carcinoma, inhibits pancreatic cancer induction, DNA damage by the lung carcinogen 4-(methylnitrosamino)-1-(3-pyridyl)-1butanone, that attenuates the increase in reactive oxygen species (ROS) and that promotes anti- and pro-angiogenic effects in different cell contexts (Algire et al., 2012; Dallaglio et al., 2014; Memmott et al., 2010; Schneider et al., 2001; Vitale-Cross et al., 2012; Zolali et al., 2019). Furthermore, epidemiological studies suggest that metformin exerts a protective effect on different types of cancer including sporadic colorectal cancer (CRC) (Chang et al., 2018; Klil-Drori et al., 2017; Kobiela et al., 2018), observations recently reinforced by a double-blind placebocontrolled/randomized trial demonstrating that metformin decreased up to $40 \%$ colorectal adenoma recurrence (Higurashi et al., 2016). An important caveat regarding the implications of many of the above mentioned in vitro studies is that the employed metformin concentrations on some cases were up to $\approx 100-150$ fold higher than those achieved in the target tissues after oral administration of therapeutic doses of metformin (Foretz et al., 2019; He and Wondisford, 2015). Nevertheless, the growing interest in metformin is evident by the number of worldwide ongoing clinical trials (337) examining its effects upon several pathologies including different cancers, fragile $\mathrm{X}$ syndrome, glaucoma, amyotrophic lateral sclerosis, cerebral palsy and HIV/AIDS (for a list of ongoing clinical trials see: https://clinicaltrials.gov/ct2/results?term=metformin\&Search= Apply\&recrs $=$ a\&recrs $=d \& a g e \_v=\& g n d r=\&$ type $\left.=\& r s l t=\right)$.

\section{$\beta$-Catenin and Metformin}

CRC development is associated with the sequential accumulation of mutations and/or deletions of tumor suppressor and oncogenes along with alterations in genetic stability. In the current model of sporadic colon cancer, the initial event that sets the stage for intestinal adenoma formation is the deregulation $\mathrm{Wnt} / \beta$-catenin signaling, an event that promotes the nuclear accumulation of $\beta$-catenin and the constitutive activation of its target genes (Cheah, 2009; Huels et al., 2015; Kinzler and Vogelstein, 1996;
Krausova and Korinek, 2014; Polakis, 2012; Sansom et al., 2004; Walther et al., 2009). In most cases, the mechanism mediating the aberrant nuclear accumulation of $\beta$-catenin involves mutations in the Adenomatous Polyposis Coli $(A P C)$ tumor suppressor gene and/or $\beta$-catenin (Bienz and Clevers, 2000; Clevers, 2006; Iwao et al., 1998; Phelps et al., 2009). In normal colonocytes, APC is part of a destruction complex that includes axis inhibition protein (Axin), glycogen synthase kinase $3 \beta$ (GSK3 $\beta$ and casein kinase 1a (CK1 1 ). The interaction of $\beta$-catenin with the destruction complex leads to its sequential phosphorylation in $\mathrm{Ser}^{45}$ by CK1 and $\mathrm{Thr}^{41} / \mathrm{Ser}^{37} / \mathrm{Ser}^{33}$ by GSK3 $\beta$ (Polakis, 2002). Phosphorylated $\beta$-catenin is then targeted for ubiquitination and later degradation by the proteasome (Clevers, 2006). Wnt binding to its receptor Frizzled, and co-receptor lowdensity lipoprotein receptor-related protein 5/6 (LRP 5/6), leads to the disassembly of the destruction complex, $\beta$ catenin $\operatorname{Ser}^{45} / \mathrm{Thr}^{41} / \mathrm{Ser}^{37} / \mathrm{Ser}^{33}$ phosphorylation inhibition and nuclear entry. Once in the nuclei, $\beta$-catenin interacts with the T-cell factor/lymphoid enhancer-binding factor (LEF/TCF) promoting the transcription of genes associated with proliferation, differentiation, adhesion and cellular migration (Clevers and Nusse, 2012; Nusse and Clevers, 2017; Valenta et al., 2012). In the case of proliferation, CYCLIN D1, one of the first reported transcriptional genes targeted in CRC by $\beta$-catenin (Niehrs and Acebron, 2012), and cMYC promote G1 phase advancement whereas cMYC induces the $S$ phase (Lecarpentier et al., 2019). Accordingly, abnormal nuclear accumulation of $\beta$-catenin promotes CyclinD1 and $\mathrm{cMyc}$ overexpression and hyper-proliferation. Lgr5 and Axin 2, which are components of the Wnt pathway, are also stem cell specific genes targeted $\mathrm{Wnt} / \beta$-catenin (Nusse and Clevers, 2017). Other genes targeted by $\beta$ catenin include Tcf1, PDK, fibronectin, MMP7, Claudin and cJun between others (for a list of genes regulated by $\beta$-catenin see: https://web.stanford.edu/group/nusselab/ cgi-bin/wnt/target_genes).

Wnt-independent phosphorylation cascades also play a central role in the control of $\beta$-catenin stability, intracellular distribution and transcriptional activity (Daugherty and Gottardi, 2007; He et al., 2007; Kriz and Korinek, 2018). For example, the phosphorylation of $\beta$-catenin at $\operatorname{Ser}^{552}$ and $\mathrm{Ser}^{675}$ by Akt or protein kinase A (PKA) promotes its nuclear translocation and transcriptional activity (Fang et al., 2007; Rey et al., 2012; Taurin et al., 2006; Taurin et al., 2008). Because T2DM is associated with chronic PI3K/Akt signaling (Hopkins et al., 2020; Lien et al., 2017), Aktmediated chronic Ser ${ }^{552} \beta$-catenin phosphorylation provides a plausible mechanism by which T2DM could potentiate CRC development. Within this framework, metformin, at concentrations found in the colon (1.5-3.5 mM) after oral administration of therapeutic doses (Paleari et al., 2018), inhibited Akt Ser ${ }^{473}$ phosphorylation and catalytic activity in CRC-derived cell lines challenged with insulin or IGF-1 (Amable et al., 2019).

Previous studies in other cancer cells demonstrated that AMPK inhibits mTORC1 activation through a mechanism that involves stimulation of TSC2 function, accumulation of Rheb-GDP (the inactive form) and direct phosphorylation 
of Raptor, (Gwinn et al., 2008; Inoki et al., 2006; Rozengurt et al., 2014). Because mTORC1 is involved in metabolism, growth and differentiation of cancer cells, it has been proposed that its inhibition by metformin is associated to metformin anticancer properties. Furthermore, a few studies indicate that metforminmediated mTORC1 inhibition also promotes autophagy in cells derived from different tumors including myeloma, pancreatic ductal adenocarcinoma, T-cell acute lymphoblastic leukemia and hepatocellular carcinoma (Candido et al., 2018; Gao et al., 2020; Grimaldi et al., 2012; Ling et al., 2017; Wang et al., 2018b). In contrast, there is little information concerning the impact of metformin/AMPK on mTORC2, the molecular complex responsible for the phosphorylation of Akt at $\mathrm{Ser}^{473}$ and $\mathrm{Thr}^{479}$, PKC classical and novel family members and glucocorticoid-induced kinase 1 (Baffi et al., 2021; Fu and Hall, 2020). Within this context, recent results revealed a marked sensitivity of CRC cells to metformin-mediated inhibition of Akt Ser ${ }^{473}$ phosphorylation (Amable et al., 2019), an exploitable vulnerability in CRC cells that can further explain the mechanisms by which metformin acts as a chemopreventive agent in bowel cancer.

Amable et al. (2019) studie also revealed that PI3K/Akt signaling suppression was mediated by AMPK and occurred upstream of Akt, very likely due to a defect in phosphatidylinositol 3,4,5-triphosphate generation. Regarding the possible mechanisms by which metformin can interfere with PI3K/Akt signaling, previous studies suggest that AMPK activity can promote a displacement of PI3K from its site of action. For example, AMPK-mediated Ser ${ }^{794}$ phosphorylation of the insulin receptor substrate 1 (IRS-1) inhibited the binding and activation of PI3K (Tzatsos and Tsichlis, 2007) while AMPK signaling shifted PI3K from its site of action at the neurite tip (Amato et al., 2011). Whether the defect observed in CRC-derived cells in response to metformin treatment was due to a block in PI3K plasma membrane translocation, inhibition of its catalytic activity or enhanced phosphatases activity needs further scrutiny.

Amable et al. (2019), studies also showed that metforminassociated PI3K/Akt signaling inhibition prevented $\beta$-catenin $\operatorname{Ser}^{552}$ phosphorylation and $\beta$-catenin-mediated transcription while promoting its plasma membrane localization. Although $\beta$-catenin does not contain nuclear localization or export signals, it shuttles between the cytoplasm and the nucleus by interacting with a variety of partners including Chibby, Axin, APC, Mucin 1, LEF-1 and BCL9 (Anthony et al., 2020; Jamieson et al., 2014; Sharma et al., 2014). Additional studies are required to elucidate how $\mathrm{Ser}^{552}$ phosphorylation inhibition affects $\beta$-catenin nucleo-cytoplasmic distribution and shuttling. Nevertheless, it is tempting to speculate that $\operatorname{Ser}^{552}$ phosphorylation enhances the interaction of $\beta$-catenin with a binding partner that favors its nuclear import and/or anchor.

\section{Metformin E-Cadherin, Fak and Metformin}

E-cadherin, a tumor suppressor, is a core component of the epithelial adherens junctions (AJ) that interacts via its cytoplasmic tail with catenin family members $\alpha, \beta$, and p120 while its extracellular domain interacts with E-cadherin present in neighboring cells (Daulagala et al., 2019). In contrast to the continuous degradation of cytoplasmic $\beta$-catenin, AJs-associated $\beta$-catenin is highly stable and associated to the regulation of E-cadherin availability at the cell surface (Ishiyama and Ikura, 2012; Mendonsa et al., 2018; Pokutta and Weis, 2007), a function shared with p120-catenin which regulates E-cadherin endocytosis (Cadwell et al., 2016; Kowalczyk and Nanes, 2012; Nanes et al., 2012). E-cadherin expression or surface localization is frequently lost or its function disrupted in many epithelialderived cancer cells including CRC (Kourtidis et al., 2017; Petrova et al., 2016). The loss of E-cadherin diminish cellcell adhesion and deregulates Wnt signaling (Heuberger and Birchmeier, 2010; Valenta et al., 2012).

$\mathrm{N}$-cadherin, another member of the cadherin family of proteins, is expressed in mesenchymal cells which are characterized by displaying a major motility and a less polarized phenotype than normal epithelial cells. N-cadherin is also found in some epithelia-derived cancer cells, a factor that contributes to their enhanced motility and invasive phenotype (Gul et al., 2017). Within this context, the transdifferentiation of epithelial cells into motile mesenchymal cells, a process known as epithelial-mesenchymal transition (EMT), play a central role in several normal and pathological processes including development, wound healing, stem cell behavior and cancer progression (Lamouille et al., 2014). Hallmarks of the EMT include destabilization of adherens junctions, tight junctions and desmosomes, critical structures necessary to maintain epithelial integrity, as well as up regulation of vimentin and $\alpha$-smooth muscle actin (Lamouille et al., 2014). Recent studies indicated that metformin inhibits EMT in cells derived from different types of cancer including gastric, colon, thyroid, breast, oral and prostate (Esparza-Lopez et al., 2019; Han et al., 2015; Valaee et al., 2017; Wang et al., 2018a; Yin et al., 2021; Zhang and Wang, 2019; Zhang et al., 2014). Several mechanisms had been proposed to explain the inhibitory effect of metformin upon EMT such as down-regulation of transcription factors (SNAIL, TWIST and ZEB), inhibition of PI3K/AKT/mTOR, MAPK, TGF $\beta$, IL- 6 and IL- 8 signaling and up regulation of miR-381 and miR-200c (Chen et al., 2020). Such variety of mechanisms could be related to the distinct origin of the cancer cells or to off-target effects since most experimental models use concentrations of metformin that exceed the levels reached in target tissues with the doses recommended to treat T2DM patients.

Matrix metalloproteinases (MMPs), a family of endopeptidases that promote the degradation of proteins in the extracellular matrix, are associated to cell proliferation, migration, and differentiation (Cui et al., 2017). In the tumor microenvironment, MMPs facilitate invasion and metastasis, two key processes associated to EMT transition. Indeed, MMPs are involved in the process that lead to the spread of metastatic cancers such as bladder, breast, colon, kidney, melanoma and sarcoma as well as various cancers including hepatocellular carcinoma, pancreatic ductal adenocarcinoma and bone (Paolillo and Schinelli, 2019; Scheau et al., 2019). Several studies indicate that MMP-2 and MMP-9, two key MMPs that promote tumor cell invasion and metastasis, are down-regulated in their expression and activity by metformin in cells derived from breast cancer, renal carcinoma, esophageal squamous cancer and human ovarian granulosa cancer (Chen et al., 2019; 
Fang et al., 2014; Jang et al., 2014; Liang et al., 2018). In several cases the down-regulation of these MMP2/9, as a results of metformin treatment, coincided with the inhibition of cell growth and migration.

Recent studies employing metformin concentrations compatible with the ones in the colon after oral administration of therapeutic doses of this drug indicate that metformin not only promoted the plasma membrane localization of $\beta$-catenin and E-cadherin but also their colocalization to de novo formed puncta along the length of CRC-derived cells contacting membranes (Amable et al., 2020). The plasma membrane redistribution of E-cadherin in response to metformin treatment was accompanied by its phosphorylation at $\mathrm{Ser}^{838 / 840}$, modifications associated to E-cadherin/ $\beta$-catenin binding and increased interaction stability between both proteins (McEwen et al., 2014). E-cadherin Ser ${ }^{838 / 840}$ conforms to a GSK3 $\beta$ recognition site, a kinase activated in CRC-derived cells in response to metformin (Amable et al., 2019). Metformin treatment was also associated with an increase in the intracellular levels of p120-catenin, a result consistent with the observation that $\beta$-catenin drives the transcription of forkhead/winged-helix transcription factors (Savage et al., 2010), which in turn down-regulate p120-catenin transcription (Mortazavi et al., 2010; Pham et al., 2017). In addition, metformin promoted the redistribution of 120 -catenin to the plasma membrane where co-localized with E-cadherin $/ \beta$-catenin, suggesting that metformin promotes the novo formation of AJs (Amable et al., 2020). Nevertheless, Amable et al. (2020), did not examine whether $\mathrm{N}$-cadherin, which is expressed in the cell lines SW-480 and HT-29 employed in those studies (Yan et al., 2015; Ye et al., 2017) was down regulated in response to metformin.

AJs, desmosomes and tight junctions (TJs) form the apical junction complex that regulates epithelial barrier function and signaling (Mehta et al., 2015; Shigetomi and Ikenouchi, 2019). Previous studies showed that AMPK exerts a protective effect on the intestinal barrier function by stimulating the formation of TJs (Chen et al., 2018; Peng et al., 2009; Wu et al., 2018; Zhang et al., 2006). Because TJs assembly is coupled to AJs formation (Campbell et al., 2017), it is plausible that AJs formation in response to metformin contributes to TJs assembly and intestinal barrier recovery after injury.

Focal adhesions (FAs) are integrin-containing structures that connect the cell to the extracellular matrix. These highly dynamic multiprotein complexes include focal adhesion kinase (FAK), a tyrosine kinase that regulates several signaling pathways associated with cell adhesion, spreading and migration (Berrier and Yamada, 2007) as well as tumor growth and metastasis (Canel et al., 2010; Sulzmaier et al., 2014; Tai et al., 2015). For example, FAK null mice fibroblasts showed a reduced rate of migration associated with FAs reorganization (Ilic et al., 1995) while FAK deficient cancer cells display large FAs and reduced motility (Chan et al., 2009; Hsia et al., 2003; Huttenlocher and Horwitz, 2011; Webb et al., 2004). Former reports indicated that metformin inhibited FAK phosphorylation in ovarian (Erices et al., 2017) and prostatic cancer cells (Yu et al., 2017) whereas a more recent study showed that, in CRC-derived cells, metformin inhibited FAK catalytic activity and ERK-dependent FAK Ser $^{910}$ phosphorylation (Hunger-Glaser et al., 2003; HungerGlaser et al., 2004; Jiang et al., 2007), a modification associated with paxillin/FAK interaction, cell spreading and migration (Chu et al., 2011; Luo et al., 2019; Vincent and Settleman, 1997). Metformin-mediated inhibition of FAK led to FAs structural changes including a reduction in their numbers and increase in their size (Amable et al., 2020), very likely through a modification of FAs turnover (Ilic et al., 1995; Iwanicki et al., 2008; Kim and Wirtz, 2013; Plotnikov et al., 2012), changes that were followed by cellular migration inhibition (Amable et al., 2020).

\section{Concluding Remarks}

In summary (Fig. 1), the most recent studies described here (Amable et al., 2019, Amable et al., 2020), indicate that metformin, at concentrations within the range of those found in human intestines after administration of therapeutic doses of this drug, targets key molecules and

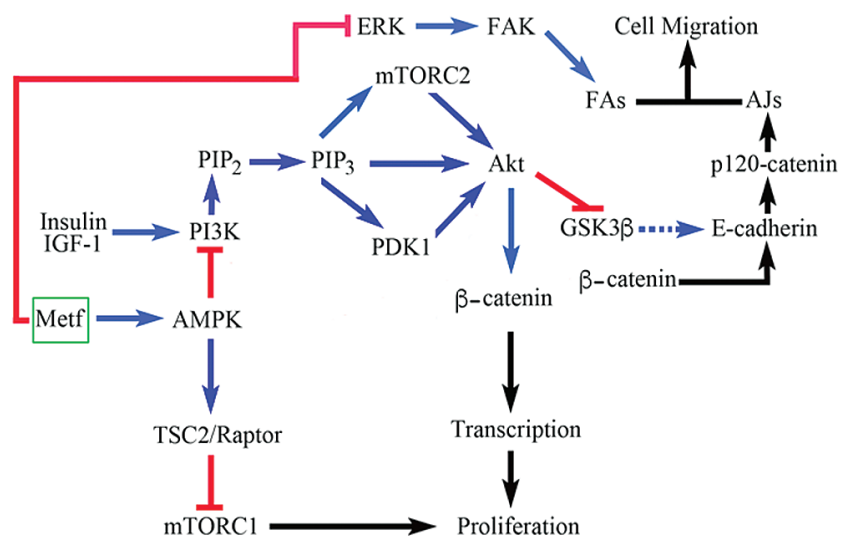

FIGURE 1. Simplified model of novel metformin targets associated to CRC development and progression. The binding of insulin and IGF-1 to their receptors triggers the activity of phosphoinositide-3 kinase (PI3K) that catalyzes the phosphorylation of PtdIns $(4,5) \mathrm{P}_{2}\left(\mathrm{PIP}_{2}\right)$ to produce PtdIns $(3,4,5) \mathrm{P}_{3}\left(\mathrm{PIP}_{3}\right)$, a second messenger that binds and recruits proteins containing a pleckstrin-homology (PH) domain such as Akt, PDK1-that phosphorylates Akt at $\mathrm{Thr}^{308}$ - and mSIN1 -a component of mTORC2 (Fu and Hall, 2020), a complex that mediates Akt $\mathrm{Ser}^{473}$ phosphorylation. Activated Akt phosphorylates $\beta$-catenin at $\mathrm{Ser}^{552}$ promoting its nuclear localization and transcription of its target genes. Metformin-mediated AMPK signaling inhibits mTORC1 activation by stimulating TSC2 -which leads to the accumulation of the inactive form Rheb-GDP- and by direct phosphorylation of Raptor -which promotes the dissociation of the mTORC1 complex. AMPK also interferes with the plasma membrane accumulation of $\mathrm{PIP}_{3}$, which leads to Akt Ser ${ }^{473}$ phosphorylation inhibition. Inhibition of Akt prevents $\beta$-catenin Ser ${ }^{552}$ phosphorylation inhibition promoting its plasma membrane localization. Akt inhibition also mediates the activation of GSK3 $\beta$ the phosphorylation of E-cadherin at $\operatorname{Ser}^{838 / 840}$ and its plasma membrane recruitment where co-localizes with $\beta$ and p120 catenins in the novo formed AJs. Metformin treatment also inhibited ERK and FAK catalytic activities, results that were accompanied by a reduction in the number and increase in the size of FAs along with cellular migration inhibition. Red Lines: inhibitory effects; blue arrows: phosphorylation/signaling cascades; black arrows: effects like redistribution of proteins/transcription/proliferation; dotted blue line: putative phosphorylation. 
signaling pathways associated with CRC development and progression. Further studies are needed in order to refine our understanding of the underlying mechanisms.

Acknowledgement: Support from the Sistema Nacional de Microscopía de la Secretaría de Ciencia, Tecnología e Innovación Productiva, Argentina, and the Microscopy and Imaging Core of the INIGEM is gratefully acknowledged.

Authors' Contribution: Conceptualization: O. R., G. A., E. M.-L. and M. E. P.; Formal Analysis: O. R., G. A., and E. M.-L.; Investigation: O. R., G. A., E. M.-L. and M. E. P.; Resources: O. R. and M. E. P.; Writing-Original Draft Preparation: O. R., G. A., and E. M.-L.; Writing-Review and Editing: O. R., G. A., and E. M.-L.; Funding Acquisition: O. R. and E. M.-L.

Ethics Approval: The research has not involved any animal or human.

Funding Statement: This study was supported by PICT 20130891 from the Fondo para la Investigación Científica y Tecnológica, Secretaría de Ciencia Tecnología e Innovación Productiva, Argentina.

Conflicts of Interest: The authors declare that they have no conflicts of interest to report regarding the present study.

\section{References}

Aleman JO, Eusebi LH, Ricciardiello L, Patidar K, Sanyal AJ, Holt PR (2014). Mechanisms of obesity-induced gastrointestinal neoplasia. Gastroenterology 146: 357-373. DOI 10.1053/j. gastro.2013.11.051.

Algire C, Moiseeva O, Deschenes-Simard X, Amrein L, Petruccelli L, Birman E, Viollet B, Ferbeyre G, Pollak MN (2012). Metformin reduces endogenous reactive oxygen species and associated DNA damage. Cancer Prevention Research (Phila) 5: 536-543. DOI 10.1158/1940-6207.CAPR-11-0536.

Amable G, Martinez-Leon E, Picco ME, di Siervi N, Davio C, Rozengurt E, Rey O (2019). Metformin inhibits b-Catenin phosphorylation on Ser-552 through an AMPK/PI3K/Akt pathway in colorectal cancer cells. International Journal of Biochemistry and Cell Biology 112: 88-94. DOI 10.1016/j. biocel.2019.05.004.

Amable G, Martinez-Leon E, Picco ME, Nemirovsky SI, Rozengurt E, Rey O (2020). Metformin inhibition of colorectal cancer cell migration is associated with rebuilt adherens junctions and FAK downregulation. Journal of Cellular Physiology 235: 8334-8344. DOI 10.1002/jcp.29677.

Amato S, Liu X, Zheng B, Cantley L, Rakic P, Man HY (2011). AMPactivated protein kinase regulates neuronal polarization by interfering with PI 3-kinase localization. Science 332: 247251. DOI 10.1126/science.1201678.

Anthony CC, Robbins DJ, Ahmed Y, Lee E (2020). Nuclear Regulation of Wnt/b-catenin signaling: It's a complex situation. Genes 11: 886. DOI 10.3390/genes11080886.

Baffi TR, Lorden G, Wozniak JM, Feichtner A, Yeung W et al. (2021). mTORC2 controls the activity of PKC and Akt by phosphorylating a conserved TOR interaction motif. Science Signaling 14: eabe4509. DOI 10.1126/scisignal.abe4509.

Berrier AL, Yamada KM (2007). Cell-matrix adhesion. Journal of Cellular Physiology 213: 565-573. DOI 10.1002/(ISSN) 1097-4652.
Bienz M, Clevers H (2000). Linking colorectal cancer to Wnt signaling. Cell 103: 311-320. DOI 10.1016/S0092-8674(00)00122-7.

Bray F, Ferlay J, Soerjomataram I, Siegel RL, Torre LA, Jemal A (2018). Global cancer statistics 2018: GLOBOCAN estimates of incidence and mortality worldwide for 36 cancers in 185 countries. CA: A Cancer Journal for Clinicians 68: 394-424. DOI 10.3322/caac.21492.

Cadwell CM, Su W, Kowalczyk AP (2016). Cadherin tales: Regulation of cadherin function by endocytic membrane trafficking. Traffic 17: 1262-1271. DOI 10.1111/tra.12448.

Campbell HK, Maiers JL, DeMali KA (2017). Interplay between tight junctions \& adherens junctions. Experimental Cell Research 358: 39-44. DOI 10.1016/j.yexcr.2017.03.061.

Candido S, Abrams SL, Steelman L, Lertpiriyapong K, Martelli AM et al. (2018). Metformin influences drug sensitivity in pancreatic cancer cells. Advances in Biological Regulation 68: 13-30. DOI 10.1016/j.jbior.2018.02.002.

Canel M, Serrels A, Miller D, Timpson P, Serrels B, Frame MC, Brunton VG (2010). Quantitative in vivo imaging of the effects of inhibiting integrin signaling via Src and FAK on cancer cell movement: Effects on E-cadherin dynamics. Cancer Research 70: 9413-9422. DOI 10.1158/0008-5472. CAN-10-1454.

Chan KT, Cortesio CL, Huttenlocher A (2009). FAK alters invadopodia and focal adhesion composition and dynamics to regulate breast cancer invasion. Journal of Cell Biology 185: 357-370. DOI 10.1083/jcb.200809110.

Chang YT, Tsai HL, Kung YT, Yeh YS, Huang CW, Ma CJ, Chiu HC, Wang JY (2018). Dose-dependent relationship between metformin and colorectal cancer occurrence among patients with type 2 diabetes-A nationwide cohort study. Translational Oncology 11: 535-541. DOI 10.1016/j. tranon.2018.02.012.

Cheah PY (2009). Recent advances in colorectal cancer genetics and diagnostics. Critical Reviews in Oncology/Hematology 69: 4555. DOI 10.1016/j.critrevonc.2008.08.001.

Chen L, Wang J, You Q, He S, Meng Q et al. (2018). Activating AMPK to restore tight junction assembly in intestinal epithelium and to attenuate experimental colitis by metformin. Frontiers in Pharmacology 9: 761. DOI 10.3389/ fphar.2018.00761.

Chen YC, Li H, Wang J (2020). Mechanisms of metformin inhibiting cancer invasion and migration. American Journal of Translational Research 12: 4885-4901.

Chen Z, Wei H, Zhao X, Xin X, Peng L, Ning Y, Wang Y, Lan Y, Zhang Q (2019). Metformin treatment alleviates polycystic ovary syndrome by decreasing the expression of MMP-2 and MMP-9 via H19/miR-29b-3p and AKT/mTOR/ autophagy signaling pathways. Journal of Cellular Physiology 234: 19964-19976. DOI 10.1002/jcp.28594.

Chu M, Iyengar R, Koshman YE, Kim T, Russell B, Martin JL, Heroux AL, Robia SL, Samarel AM (2011). Serine-910 phosphorylation of focal adhesion kinase is critical for sarcomere reorganization in cardiomyocyte hypertrophy. Cardiovascular Research 92: 409-419. DOI 10.1093/cvr/cvr247.

Clevers $\mathrm{H}$ (2006). Wnt/b-catenin signaling in development and disease. Cell 127: 469-480. DOI 10.1016/j.cell.2006.10.018.

Clevers H, Nusse R (2012). Wnt/b-catenin signaling and disease. Cell 149: 1192-1205. DOI 10.1016/j.cell.2012.05.012.

Cohen DH, LeRoith D (2012). Obesity, type 2 diabetes, and cancer: The insulin and IGF connection. Endocrine-Related Cancer 19: F27-F45. DOI 10.1530/ERC-11-0374. 
Conza D, Mirra P, Cali G, Insabato L, Fiory F, Beguinot F, Ulianich L (2021). Metformin dysregulates the unfolded protein response and the WNT/b-catenin pathway in endometrial cancer cells through an AMPK-independent mechanism. Cells 10: 1067. DOI 10.3390/cells10051067.

Cui N, Hu M, Khalil RA (2017). Biochemical and biological attributes of matrix metalloproteinases. Progress in Molecular Biology and Translational Science 147: 1-73. DOI 10.1016/bs. pmbts.2017.02.005.

Cusi K, Consoli A, DeFronzo RA (1996). Metabolic effects of metformin on glucose and lactate metabolism in noninsulin-dependent diabetes mellitus. Journal of Clinical Endocrinology and Metabolism 81: 4059-4067. DOI 10.1210/jcem.81.11.8923861.

Dallaglio K, Bruno A, Cantelmo AR, Esposito AI, Ruggiero L et al. (2014). Paradoxic effects of metformin on endothelial cells and angiogenesis. Carcinogenesis 35: 1055-1066. DOI 10.1093/carcin/bgu001.

Daugherty RL, Gottardi CJ (2007). Phospho-regulation of b-catenin adhesion and signaling functions. Physiology (Bethesda) 22: 303-309. DOI 10.1152/physiol.00020.2007.

Daulagala AC, Bridges MC, Kurtidis A (2019). E-Cadherin beyond structure: a signaling hub in colon meostasis and disease. International Journal of Molecular Sciences 28: 2576. DOI 10.3390/ijms20112576.

El-Mir MY, Nogueira V, Fontaine E, Averet N, Rigoulet M, Leverve X (2000). Dimethylbiguanide inhibits cell respiration via an indirect effect targeted on the respiratory chain complex I. Journal of Biological Chemistry 275: 223-228. DOI 10.1074/ jbc.275.1.223.

Erices R, Cubillos S, Aravena R, Santoro F, Marquez M et al. (2017). Diabetic concentrations of metformin inhibit plateletmediated ovarian cancer cell progression. Oncotarget 8: 20865-20880. DOI 10.18632/oncotarget.15348.

Esparza-Lopez J, Alvarado-Munoz JF, Escobar-Arriaga E, UlloaAguirre A, de Jesus Ibarra-Sanchez M (2019). Metformin reverses mesenchymal phenotype of primary breast cancer cells through STAT3/NF-kappaB pathways. BMC Cancer 19: 728 . DOI 10.1186/s12885-019-5945-1.

Fang D, Hawke D, Zheng Y, Xia Y, Meisenhelder J, Nika H, Lu Z (2007). Phosphorylation of b-catenin by AKT promotes bcatenin transcriptional activity. Journal of Biological Chemistry 282: 11221-11229. DOI 10.1074/jbc.M611871200.

Fang Z, Xu X, Zhou Z, Xu Z, Liu Z (2014). Effect of metformin on apoptosis, cell cycle arrest migration and invasion of A498 cells. Molecular Medicine Reports 9: 2251-2256. DOI 10.3892/mmr.2014.2097.

Foretz M, Guigas B, Viollet B (2019). Understanding the glucoregulatory mechanisms of metformin in type 2 diabetes mellitus. Nature Reviews in Endocrinology 15: 569589. DOI 10.1038/s41574-019-0242-2.

Foretz M, Hebrard S, Leclerc J, Zarrinpashneh E, Soty M, Mithieux G, Sakamoto K, Andreelli F, Viollet B (2010). Metformin inhibits hepatic gluconeogenesis in mice independently of the LKB1/AMPK pathway via a decrease in hepatic energy state. Journal of Clinical Investigation 120: 2355-2369. DOI 10.1172/JCI40671.

Fu W, Hall MN (2020). Regulation of mTORC2 signaling. Genes 11: 1045. DOI 10.3390/genes11091045.

Gallagher EJ, LeRoith D (2011). Minireview: IGF, insulin, and cancer. Endocrinology 152: 2546-2551. DOI 10.1210/en.2011-0231.

Gao C, Fang L, Zhang H, Zhang WS, Li XO et al. (2020). Metformin induces autophagy via the AMPK-mTOR signaling pathway in human hepatocellular carcinoma cells. Cancer Management and Research 12: 5803-5811. DOI 10.2147/CMAR.S257966.

Garrido MP, Salvatierra R, Valenzuela-Valderrama M, Vallejos C, Bruneau N, Hernandez A, Vega M, Selman A, Quest AFG, Romero C (2020). Metformin reduces NGF-induced tumour promoter effects in epithelial ovarian cancer cells. Pharmaceuticals 13: 315. DOI 10.3390/ph13100315.

Gonzalez N, Prieto I, Del Puerto-Nevado L, Portal-Nunez S, Ardura JA et al. (2017). 2017 update on the relationship between diabetes and colorectal cancer: Epidemiology, potential molecular mechanisms and therapeutic implications. Oncotarget 8: 18456-18485. DOI 10.18632/oncotarget.14472.

Grimaldi C, Chiarini F, Tabellini G, Ricci F, Tazzari PL et al. (2012). AMP-dependent kinase/mammalian target of rapamycin complex 1 signaling in T-cell acute lymphoblastic leukemia: Therapeutic implications. Leukemia 26: 91-100. DOI 10.1038/leu.2011.269.

Gul IS, Hulpiau P, Saeys Y, van Roy F (2017). Evolution and diversity of cadherins and catenins. Experimental Cell Research 358: 3-9. DOI 10.1016/j.yexcr.2017.03.001.

Gwinn DM, Shackelford DB, Egan DF, Mihaylova MM, Mery A, Vasquez DS, Turk BE, Shaw RJ (2008). AMPK phosphorylation of raptor mediates a metabolic checkpoint. Molecular Cell 30: 214-226. DOI 10.1016/j.molcel.2008.03.003.

Han B, Cui H, Kang L, Zhang X, Jin Z, Lu L, Fan Z (2015). Metformin inhibits thyroid cancer cell growth, migration, and EMT through the mTOR pathway. Tumour Biology 36: 62956304. DOI 10.1007/s13277-015-3315-4.

He L, Sabet A, Djedjos S, Miller R, Sun X, Hussain MA, Radovick S, Wondisford FE (2009). Metformin and insulin suppress hepatic gluconeogenesis through phosphorylation of CREB binding protein. Cell 137: 635-646. DOI 10.1016/j.cell.2009.03.016.

He L, Wondisford FE (2015). Metformin action: Concentrations matter. Cell Metabolism 21: 159-162. DOI 10.1016/j. cmet.2015.01.003.

He XC, Yin T, Grindley JC, Tian Q, Sato T et al. (2007). PTENdeficient intestinal stem cells initiate intestinal polyposis. Nature Genetics 39: 189-198. DOI 10.1038/ng1928.

Heuberger J, Birchmeier W (2010). Interplay of cadherin-mediated cell adhesion and canonical Wnt signaling. Cold Spring Harorb Perspectives in Biology 2: a002915. DOI 10.1101/ cshperspect.a002915.

Higurashi T, Hosono K, Takahashi H, Komiya Y, Umezawa S et al. (2016). Metformin for chemoprevention of metachronous colorectal adenoma or polyps in post-polypectomy patients without diabetes: A multicentre double-blind, placebocontrolled, randomised phase 3 trial. The Lancet Oncology 17: 475-483. DOI 10.1016/S1470-2045(15)00565-3.

Hopkins BD, Goncalves MD, Cantley LC (2020). Insulin-PI3K signalling: An evolutionarily insulated metabolic driver of cancer. Nature Review Endocrinology 16: 276-283. DOI 10.1038/s41574-020-0329-9.

Hsia DA, Mitra SK, Hauck CR, Streblow DN, Nelson JA et al. (2003). Differential regulation of cell motility and invasion by FAK. Journal of Cell Biology 160: 753-767. DOI 10.1083/ jcb.200212114.

Huels DJ, Ridgway RA, Radulescu S, Leushacke M, Campbell AD et al. (2015). E-cadherin can limit the transforming properties of activating b-catenin mutations. The EMBO Journal 34: 2321-2333. DOI 10.15252/embj.201591739.

Hundal RS, Krssak M, Dufour S, Laurent D, Lebon V et al. (2000). Mechanism by which metformin reduces glucose 
production in type 2 diabetes. Diabetes 49: 2063-2069. DOI 10.2337/diabetes.49.12.2063.

Hunger-Glaser I, Fan RS, Perez-Salazar E, Rozengurt E (2004). PDGF and FGF induce focal adhesion kinase (FAK) phosphorylation at Ser-910: Dissociation from Tyr-397 phosphorylation and requirement for ERK activation. Journal of Cellular Physiology 200: 213-222. DOI 10.1002/ (ISSN)1097-4652.

Hunger-Glaser I, Salazar EP, Sinnett-Smith J, Rozengurt E (2003). Bombesin, lysophosphatidic acid, and epidermal growth factor rapidly stimulate focal adhesion kinase phosphorylation at Ser-910: Requirement for ERK activation. Journal of Biological Chemestry 278: 22631-22643. DOI 10.1074/jbc.M210876200.

Huttenlocher A, Horwitz AR (2011). Integrins in cell migration. Cold Spring Harbor Perspectives in Biology 3: a005074. DOI 10.1101/cshperspect.a005074.

Ilic D, Furuta Y, Kanazawa S, Takeda N, Sobue K, Nakatsuji N, Nomura S, Fujimoto J, Okada M, Yamamoto T (1995). Reduced cell motility and enhanced focal adhesion contact formation in cells from FAK-deficient mice. Nature 377: 539-544. DOI 10.1038/377539a0.

Inoki K, Ouyang H, Zhu T, Lindvall C, Wang Y, Zhang X, Guan KL (2006). TSC2 integrates Wnt and energy signals via a coordinated phosphorylation by AMPK and GSK3 to regulate cell growth. Cell 126: 955-968. DOI 10.1016/j.cell.2006.06.055.

Ishiyama N, Ikura M (2012). The three-dimensional structure of the cadherin-catenin complex. Sub-Cellular Biochemistry 60: 3962. DOI 10.1007/978-94-007-4186-7.

Isoda K, Young JL, Zirlik A, MacFarlane LA, Tsuboi N, Gerdes N, Libby P (2006). Metformin inhibits proinflammatory responses and nuclear factor-kappaB in human vascular wall cells. Arteriosclerosis, Thrombosis and Vascular Biology 26: 611-617. DOI 10.1161/01.ATV.0000201938.78044.75.

Iwanicki MP, Vomastek T, Tilghman RW, Martin KH, Banerjee J, Wedegaertner PB, Parsons JT (2008). FAK, PDZ-RhoGEF and ROCKII cooperate to regulate adhesion movement and trailing-edge retraction in fibroblasts. Journal of Cell Science 121: 895-905. DOI 10.1242/jcs.020941.

Iwao K, Nakamori S, Kameyama M, Imaoka S, Kinoshita M, Fukui T, Miyoshi Y (1998). Activation of th b-catenin gene by interstitial deletions involving exon 3 in primary colorectal carcinomas without adenomatous polyposis coli mutations. Cancer Research 58: 1021-1026.

Jamieson C, Sharma M, Henderson BR (2014). Targeting the b-catenin nuclear transport pathway in cancer. Semininars in Cancer Biology 27: 20-29. DOI 10.1016/j.semcancer.2014.04.012.

Jang SY, Kim A, Kim JK, Kim C, Cho YH, Kim JH, Lee JY (2014). Metformin inhibits tumor cell migration via downregulation of MMP9 in tamoxifen-resistant breast cancer cells. Anticancer Research 34: 4127-4134.

Jiang X, Sinnett-Smith J, Rozengurt E (2007). Differential FAK phosphorylation at Ser-910, Ser-843 and Tyr-397 induced by angiotensin II, LPA and EGF in intestinal epithelial cells. Cellular Signaling 19: 1000-1010. DOI 10.1016/j.cellsig.2006.11.004.

Johanns M, Lai YC, Hsu MF, Jacobs R, Vertommen D et al. (2016). AMPK antagonizes hepatic glucagon-stimulated cyclic AMP signalling via phosphorylation-induced activation of cyclic nucleotide phosphodiesterase 4B. Nature Communications 7: 10856. DOI 10.1038/ncomms10856.

Kim DH, Wirtz D (2013). Focal adhesion size uniquely predicts cell migration. FASEB Journal 27: 1351-1361. DOI 10.1096/fj.12220160 .
King TD, Song L, Jope RS (2006). AMP-activated protein kinase (AMPK) activating agents cause dephosphorylation of Akt and glycogen synthase kinase-3. Biochemical Pharmacology 71: 1637-1647. DOI 10.1016/j.bcp.2006.03.005.

Kinzler KW, Vogelstein B (1996). Lessons from hereditary colorectal cancer. Cell 87: 159-170. DOI 10.1016/S0092-8674(00) 81333-1.

Klil-Drori AJ, Azoulay L, Pollak MN (2017). Cancer, obesity, diabetes, and antidiabetic drugs: Is the fog clearing? Nature Reviews Clinical Oncology 14: 85-99. DOI 10.1038/ nrclinonc.2016.120.

Kobiela J, Dobrzycka M, Jedrusik P, Kobiela P, Spychalski P, Sledzinski Z, Zdrojewski T (2018). Metformin and colorectal cancer-A systematic review. Experimental and Clinical Endocrinology \& Diabetes 127: 0621-8830. DOI 10.1055/a-0621-8830.

Kourtidis A, Lu R, Pence LJ, Anastasiadis PZ (2017). A central role for cadherin signaling in cancer. Experimental Cell Research 358: 78-85. DOI 10.1016/j.yexcr.2017.04.006.

Kowalczyk AP, Nanes BA (2012). Adherens junction turnover: Regulating adhesion through cadherin endocytosis, degradation, and recycling. Subcellular Biochemistry 60: 197-222. DOI 10.1007/978-94-007-4186-7.

Krausova M, Korinek V (2014). Wnt signaling in adult intestinal stem cells and cancer. Cellular Signalling 26: 570-579. DOI 10.1016/j.cellsig.2013.11.032.

Kriz V, Korinek V (2018). Wnt, RSPO and Hippo signalling in the intestine and intestinal stem cells. Genes 9: 20. DOI 10.3390/genes 9010020 .

Lamouille S, Xu J, Derynck R (2014). Molecular mechanisms of epithelialmesenchymal transition. Nature Reviews in Molecular and Cellular Biology 15: 178-196. DOI 10.1038/nrm3758.

Lecarpentier Y, Schussler O, Hebert JL, Vallee A (2019). Multiple targets of the canonical WNT/b-catenin signaling in cancers. Frontiers in Oncology 9: 1248. DOI 10.3389/fonc.2019.01248.

Liang F, Wang YG, Wang C (2018). Metformin inhibited growth, invasion and metastasis of esophageal squamous cell carcinoma in vitro and in vivo. Cellular Physiology and Biochemistry 51: 1276-1286. DOI 10.1159/000495539.

Lien EC, Dibble CC, Toker A (2017). PI3K signaling in cancer: Beyond AKT. Current Opinion in Cell Biology 45: 62-71. DOI 10.1016/j.ceb.2017.02.007.

Ling S, Song L, Fan N, Feng T, Liu L et al. (2017). Combination of metformin and sorafenib suppresses proliferation and induces autophagy of hepatocellular carcinoma via targeting the mTOR pathway. International Journal of Oncology 50: 297-309. DOI 10.3892/ijo.2016.3799.

Luo L, Matthews JD, Robinson BS, Jones RM (2019). Vibrio parahaemolyticus VopA is a potent inhibitor of cell migration and apoptosis in the intestinal epithelium of Drosophila melanogaster. Infection and Immunity 87: 1920. DOI 10.1128/IAI.00669-18.

Marcucci F, Romeo E, Caserta CA, Rumio C, Lefoulon F (2020). Context-dependent pharmacological effects of metformin on the immune system. Trends in Pharmacological Sciences 41: 162-171. DOI 10.1016/j.tips.2020.01.003.

McEwen AE, Maher MT, Mo R, Gottardi CJ (2014). E-cadherin phosphorylation occurs during its biosynthesis to promote its cell surface stability and adhesion. Molecular Biology of the Cell 25: 2365-2374. DOI 10.1091/mbc.e14-01-0690.

Mehta S, Nijhuis A, Kumagai T, Lindsay J, Silver A (2015). Defects in the adherens junction complex (E-cadherin/b-catenin) in 
inflammatory bowel disease. Cell Tissue Research 360: 749760. DOI 10.1007/s00441-014-1994-6.

Melnik S, Dvornikov D, Muller-Decker K, Depner S, Stannek P et al. (2018). Cancer cell specific inhibition of Wnt/b-catenin signaling by forced intracellular acidification. Cell Discovery 4: 37. DOI 10.1038/s41421-018-0033-2.

Memmott RM, Mercado JR, Maier CR, Kawabata S, Fox SD, Dennis PA (2010). Metformin prevents tobacco carcinogen-induced lung tumorigenesis. Cancer Prevention Research (Phila) 3: 1066-1076. DOI 10.1158/1940-6207.CAPR-10-0055.

Mendonsa AM, Na TY, Gumbiner BM (2018). E-cadherin in contact inhibition and cancer. Oncogene 37: 4769-4780. DOI 10.1038/s41388-018-0304-2.

Miller RA, Chu Q, Xie J, Foretz M, Viollet B, Birnbaum MJ (2013). Biguanides suppress hepatic glucagon signalling by decreasing production of cyclic AMP. Nature 494: 256-260. DOI 10.1038/nature11808.

Mortazavi F, An J, Dubinett S, Rettig M (2010). p120-Catenin is transcriptionally downregulated by FOXC2 in non-small cell lung cancer cells. Molecular Cancer Research 8: 762774. DOI 10.1158/1541-7786.MCR-10-0004.

Nanes BA, Chiasson-MacKenzie C, Lowery AM, Ishiyama N, Faundez V, Ikura M, Kowalczyk AP (2012). p120-Catenin binding masks an endocytic signal conserved in classical cadherins. Journal of Cell Biology 199: 365-380. DOI 10.1083/jcb.201205029.

Niehrs C, Acebron SP (2012). Mitotic and mitogenic Wnt signalling. The EMBO Journal 31: 2705-2713. DOI 10.1038/emboj.2012.124.

Nusse R, Clevers H (2017). Wnt/b-catenin signaling, disease, and emerging therapeutic modalities. Cell 169: 985-999. DOI 10.1016/j.cell.2017.05.016.

Paleari L, Burhenne J, Weiss J, Foersch S, Roth W et al. (2018). High accumulation of metformin in colonic tissue of subjects with diabetes or the metabolic syndrome. Gastroenterology 154: 1543-1545. DOI 10.1053/j.gastro.2017.12.040.

Paolillo M, Schinelli S (2019). Extracellular matrix alterations in metastatic processes. International Journal of Molecular Science 20: 4947. DOI 10.3390/ijms20194947.

Park SY, Kim D, Kee SH (2019). Metformin-activated AMPK regulates b-catenin to reduce cell proliferation in colon carcinoma RKO cells. Oncology Letters 17: 2695-2702. DOI 10.3892/ol.2019.9892.

Peng L, Li ZR, Green RS, Holzman IR, Lin J (2009). Butyrate enhances the intestinal barrier by facilitating tight junction assembly via activation of AMP-activated protein kinase in Caco-2 cell monolayers. Journal of Nutrition 139: 16191625. DOI 10.3945/jn.109.104638.

Petrova YI, Schecterson L, Gumbiner BM (2016). Roles for Ecadherin cell surface regulation in cancer. Molecular Biology of the Cell 27: 3233-3244. DOI 10.1091/mbc.E1601-0058.

Pham TND, Perez White BE, Zhao H, Mortazavi F, Tonetti DA (2017). Protein kinase C alpha enhances migration of breast cancer cells through FOXC2-mediated repression of p120-catenin. BMC Cancer 17: 832. DOI 10.1186/ s12885-017-3827-y.

Phelps RA, Chidester S, Dehghanizadeh S, Phelps J, Sandoval IT, Rai $\mathrm{K}$, Jones DA (2009). A two-step model for colon adenoma initiation and progression caused by APC loss. Cell 137: 623-634. DOI 10.1016/j.cell.2009.02.037.

Plotnikov SV, Pasapera AM, Sabass B, Waterman CM (2012). Force fluctuations within focal adhesions mediate ECM-rigidity sensing to guide directed cell migration. Cell 151: $1513-$ 1527. DOI 10.1016/j.cell.2012.11.034.

Pokutta S, Weis WI (2007). Structure and mechanism of cadherins and catenins in cell-cell contacts. Annual Review of Cell Development Biology 23: 237-261. DOI 10.1146/annurev. cellbio.22.010305.104241.

Polakis P (2002). Casein kinase 1: A Wnt'er of disconnect. Current Biology 12: R499-R501. DOI 10.1016/S0960-9822(02)00969-7.

Polakis P (2012). Wnt signaling in cancer. Cold Spring Harbor Perspectives in Biology 4: a008052. DOI 10.1101/cshperspect. a008052.

Rey O, Chang W, Bikle D, Rozengurt N, Young SH, Rozengurt E (2012). Negative cross-talk between calcium-sensing receptor and b-catenin signaling systems in colonic epithelium. Journal of Biological Chemistry 287: 1158-1167. DOI 10.1074/jbc.M111.274589.

Rozengurt E, Soares HP, Sinnett-Smith J (2014). Suppression of feedback loops mediated by PI3K/mTOR induces multiple overactivation of compensatory pathways: An unintended consequence leading to drug resistance. Molecular Cancer Therapeutics 13: 2477-2488. DOI 10.1158/1535-7163.MCT14-0330.

Saini N, Yang X (2018). Metformin as an anti-cancer agent: Actions and mechanisms targeting cancer stem cells. Acta Biochimica Biophysica Sinica 50: 133-143. DOI 10.1093/abbs/gmx106.

Sansom OJ, Reed KR, Hayes AJ, Ireland H, Brinkmann H, Newton IP, Winton DJ et al. (2004). Loss of Apc in vivo immediately perturbs Wnt signaling, differentiation, and migration. Genes \& Development 18: 1385-1390. DOI 10.1101/gad.287404.

Savage J, Voronova A, Mehta V, Sendi-Mukasa F, Skerjanc IS (2010). Canonical Wnt signaling regulates Foxc1/2 expression in P19 cells. Differentiation; Research in Biological Diversity 79: 3140. DOI 10.1016/j.diff.2009.08.008.

Scheau C, Badarau IA, Costache R, Caruntu C, Mihai GL, Didilescu AC, Constantin C, Neagu M (2019). The role of matrix metalloproteinases in the epithelial-mesenchymal transition of hepatocellular carcinoma. Analytical Cellular Pathology (Amst) 2019: 1-10. DOI 10.1155/2019/9423907.

Schneider MB, Matsuzaki H, Haorah J, Ulrich A, Standop J, Ding XZ, Pour PM (2001). Prevention of pancreatic cancer induction in hamsters by metformin. Gastroenterology 120: $1263-$ 1270. DOI 10.1053/gast.2001.23258.

Sharma M, Johnson M, Brocardo M, Jamieson C, Henderson BR (2014). Wnt signaling proteins associate with the nuclear pore complex: Implications for cancer. Advances in Experimental Medicine and Biology 773: 353-372. DOI 10.1007/978-1-4899-8032-8.

Shaw RJ, Lamia KA, Vasquez D, Koo SH, Bardeesy N, Depinho RA, Cantley LC (2005). The kinase LKB1 mediates glucose homeostasis in liver and therapeutic effects of metformin. Science 310: 1642-1646. DOI 10.1126/science.1120781.

Shigetomi K, Ikenouchi J (2019). Cell adhesion structures in epithelial cells are formed in dynamic and cooperative ways. BioEssays 41: 1800227. DOI 10.1002/bies.201800227.

Sulzmaier FJ, Jean C, Schlaepfer DD (2014). FAK in cancer: Mechanistic findings and clinical applications. Nature Reviews Cancer 14: 598-610. DOI 10.1038/nrc3792.

Tai YL, Chen LC, Shen TL (2015). Emerging roles of focal adhesion kinase in cancer. Biomedical Research International 2015: 113. DOI $10.1155 / 2015 / 690690$.

Takatani T, Minagawa M, Takatani R, Kinoshita K, Kohno Y (2011). AMP-activated protein kinase attenuates Wnt/b-catenin 
signaling in human osteoblastic Saos-2 cells. Molecular and Cellular Endocrinology 339: 114-119. DOI 10.1016/j. mce.2011.04.003.

Taurin S, Sandbo N, Qin Y, Browning D, Dulin NO (2006). Phosphorylation of b-catenin by cyclic AMP-dependent protein kinase. Journal of Biological Chemistry 281: 99719976. DOI 10.1074/jbc.M508778200.

Taurin S, Sandbo N, Yau DM, Sethakorn N, Dulin NO (2008). Phosphorylation of $\mathrm{b}$-catenin by PKA promotes ATPinduced proliferation of vascular smooth muscle cells. American Journal of Physiology: Cellular Physiology 294: C1169-C1174. DOI 10.1152/ajpcell.00096.2008.

Tzatsos A, Tsichlis PN (2007). Energy depletion inhibits phosphatidylinositol 3-kinase/Akt signaling and induces apoptosis via AMP-activated protein kinase-dependent phosphorylation of IRS-1 at Ser-794. Journal of Biological Chemistry 282: 18069-18082. DOI 10.1074/jbc.M610101200.

Unnikrishnan R, Pradeepa R, Joshi SR, Mohan V (2017). Type 2 diabetes: Demystifying the global epidemic. Diabetes 66: 1432-1442. DOI 10.2337/db16-0766.

Ursini F, Russo E, Pellino G, D’Angelo S, Chiaravalloti A, de Sarro G, Manfredini R, de Giorgio R (2018). Metformin and autoimmunity: A "new deal" of an old drug. Frontiers in Immunology 9: 1236. DOI 10.3389/fimmu.2018.01236.

Valaee S, Yaghoobi MM, Shamsara M (2017). Metformin inhibits gastric cancer cells metastatic traits through suppression of epithelial-mesenchymal transition in a glucose-independent manner. PLoS One 12: e0174486. DOI 10.1371/journal. pone.0174486.

Valenta T, Hausmann G, Basler K (2012). The many faces and functions of b-catenin. EMBO Journal 31: 2714-2736. DOI 10.1038/emboj.2012.150.

Vincent S, Settleman J (1997). The PRK2 kinase is a potential effector target of both Rho and Rac GTPases and regulates actin cytoskeletal organization. Molecular and Cellular Biology 17: 2247-2256. DOI 10.1128/MCB.17.4.2247.

Vitale-Cross L, Molinolo AA, Martin D, Younis RH, Maruyama T, Patel V, Gutkind JS (2012). Metformin prevents the development of oral squamous cell carcinomas from carcinogen-induced premalignant lesions. Cancer Prevention Research (Phila) 5: 562-573. DOI 10.1158/19406207.CAPR-11-0502.

Walther A, Johnstone E, Swanton C, Midgley R, Tomlinson I, Kerr D (2009). Genetic prognostic and predictive markers in colorectal cancer. Nature Reviews Cancer 9: 489-499. DOI 10.1038/nrc2645.

Wang Y, Wu Z, Hu L (2018a). The regulatory effects of metformin on the [SNAIL/miR-34]: [ZEB/miR-200] system in the epithelial-mesenchymal transition(EMT) for colorectal cancer(CRC). European Journal of Pharmacology 834: 4553. DOI 10.1016/j.ejphar.2018.07.006.

Wang Y, Xu W, Yan Z, Zhao W, Mi J, Li J, Yan H (2018b). Metformin induces autophagy and G0/G1 phase cell cycle arrest in myeloma by targeting the AMPK/mTORC1 and mTORC2 pathways. Journal of Experimental Clinical Cancer Research 37: 63. DOI 10.1186/s13046-018-0731-5.

Webb DJ, Donais K, Whitmore LA, Thomas SM, Turner CE, Parsons JT, Horwitz AF (2004). FAK-Src signalling through paxillin, ERK and MLCK regulates adhesion disassembly. Nature Cell Biology 6: 154-161. DOI 10.1038/ncb1094.

Wu W, Wang S, Liu Q, Shan T, Wang Y (2018). Metformin protects against LPS-induced intestinal barrier dysfunction by activating AMPK pathway. Molecular Pharmaceutics 15: 3272-3284. DOI 10.1021/acs.molpharmaceut.8b00332.

Yan X, Yan L, Liu S, Shan Z, Tian Y, Jin Z (2015). N-cadherin, a novel prognostic biomarker, drives malignant progression of colorectal cancer. Molecular Medicine Reports 12: 29993006. DOI 10.3892/mmr.2015.3687.

Ye Q, Su L, Chen D, Zheng W, Liu Y (2017). Astragaloside IV induced miR-134 expression reduces EMT and increases chemotherapeutic sensitivity by suppressing CREB1 signaling in colorectal cancer cell line SW-480. Cellular Physiology and Biochemistry 43: 1617-1626. DOI 10.1159/ 000482025

Yin W, Liu Y, Liu X, Ma X, Sun B, Yu Z (2021). Metformin inhibits epithelial-mesenchymal transition of oral squamous cell carcinoma via the mTOR/HIF-1alpha/PKM2/STAT3 pathway. Oncology Letters 21: 1. DOI 10.3892/ol.2020.12292.

Yu T, Wang C, Yang J, Guo Y, Wu Y, Li X (2017). Metformin inhibits SUV39H1-mediated migration of prostate cancer cells. Oncogenesis 6: e324. DOI 10.1038/oncsis.2017.28.

Zhang C, Wang Y (2019). Metformin attenuates cells stemness and epithelialmesenchymal transition in colorectal cancer cells by inhibiting the Wnt3a/b-catenin pathway. Molecular Medicine Reports 19: 1203-1209. DOI 10.3892/mmr.2018.9765.

Zhang J, Shen C, Wang L, Ma Q, Xia P, Qi M, Yang M, Han B (2014). Metformin inhibits epithelial-mesenchymal transition in prostate cancer cells: Involvement of the tumor suppressor miR30a and its target gene SOX4. Biochemical and Biophysical Research Communications 452: 746-752. DOI 10.1016/j.bbrc.2014.08.154.

Zhang L, Li J, Young LH, Caplan MJ (2006). AMP-activated protein kinase regulates the assembly of epithelial tight junctions. Proceedings of the National Academy of Sciences of the United States of America 103: 17272-17277. DOI 10.1073/ pnas. 0608531103.

Zhou G, Myers R, Li Y, Chen Y, Shen X et al. (2001). Role of AMPactivated protein kinase in mechanism of metformin action. Journal of Clinical Investigation 108: 1167-1174. DOI 10.1172/JCI13505.

Zolali E, Rezabakhsh A, Nabat E, Jaberi H, Rahbarghazi R, Garjani A (2019). Metformin effect on endocan biogenesis in human endothelial cells under diabetic condition. Archives of Medical Research 50: 304-314. DOI 10.1016/ j.arcmed.2019.08.012. 